\title{
ACCÉS A LA TERRA, DESAGRARITZACIÓ I REAGRARITZACIÓ: DISCURSOS DES D'UN BANC DE TERRES AL CAMP DE TARRAGONA
}

MARC GONZÁlez-PuENTE

TFM Màster Antropologia Urbana, Migracions i Intervenció Social Doctorat en Antropologia i Comunicació. Departament d'Antropologia, Filosofia i Treball Social. Universitat Rovira i Virgili marcgpuente@gmail.com / marc.gonzalez@urv.cat

RESUM: L'article explora les pràctiques, creences, valors i imaginaris de persones vinculades a un banc de terres comarcal (BdT), un programa de reagrarització centrat a facilitar l'accés a la terra. Arran dels processos de desagrarització, la terra ha perdut, per moltes persones que en posseeixen, el valor com a factor de producció essencial i ha passat a tenir un valor simbòlic lligat a la conservació del patrimoni propi, la identitat i la memòria. D'altra banda, la mercantilització, l'abandonament i la mateixa dinàmica dels mercats locals dificulten l'accés a la terra per part de persones potencialment interessades. En aquest context, el BdT actua democratitzant l'accés a la terra i retornant a la pagesia el factor productiu definitori. Per tant, actua en sinergia amb l'ideari de la nova pagesia que encarna processos de reagrarització com a resistències locals i simultànies als contextos globals de desagrarització. Finalment, l'escala del programa, la proximitat i les relacions de confiança han estat identificats com factors que poden garantir o minar l'assentament en un territori dels programes de reagrarització orientats a l'accés a la terra.

PARAULES CLAU: reagrarització; desagrarització; accés a la terra; banc de terres; Camp de Tarragona 
ABSTRACT: This paper explores the practices, beliefs, values and imaginings of people participating in a regional Land Bank (LB), a re-agrarianisation program focused on facilitating access to land. As a result of de-agrarianisation, the value of farmland as an essential element of production has been lost for landowners. Land has thus become a symbolic resource linked to heritage, identity and memory conservation. In addition, land commodification, land abandonment and the local markets dynamics make it difficult to access land for those who are potentially interested. In this context, the LB appears to be able to democratize access to land and thus the notion of land as a productive factor and important resource. Therefore, it can act in synergy with the new ideology of land ownership which is embodying re-agrarianisation processes understood as simultaneous local resistances to global de-agrarianisation contexts. Finally, scale, proximity and trust in the programme have been identified as factors that can influence the sustaining or undermining of re-agrarianisation initiatives focused on access to land.

KEYWORDS: re-agrarianisation; de-agrarianisation; access to land; Land Bank; Camp de Tarragona 


\section{Introducció}

Els processos de desagrarització global han comportat la precarització de la reproducció de les comunitats rurals, eminentment pageses, arreu del planeta (Soronellas, 2012). La desagrarització va arribar acompanyada de dicotomies teòriques i pràctiques entre el model agrari de la pagesia lligada a la terra i el de la modernització agrària, relacionada amb el progrés i caracteritzada per l'eficàcia, l'eficiència i la mercantilització dels factors productius (Van der Ploeg, 2018). D’aquesta manera, les polítiques públiques i el mercat han donat pas a una nova configuració dels espais i les societats que desvincula la terra de l'ésser humà i la cosifica, per transformar-la, d'acord amb Polanyi (1989), en una nova mercaderia fictícia, juntament amb el treball i els diners.

Aquests canvis sobre el sector agrari han generat, d'una banda, processos globals d'intensificació agrícola i d'abandonament de terres que han suposat la desaparició de bona part de les terres productives en aquelles localitzacions menys susceptibles de ser mecanitzades (Corbelle i Crecente, 2008; Ustaoglu i Collier, 2018; Terres et alii, 2013; Murua et alii, 2012; Pointereau et alii, 2008). D'altra banda, s'han generat mercats de la terra descompensats, amb externalitats positives i caracteritzats per l'especulació que, juntament amb unes baixes rendes agràries, fan que l'ús de la terra per a la producció agrícola sovint sigui una estratègia econòmicament inviable (Ustaoglu i Collier, 2018; Hubacek i Van den Bergh, 2006). Enfront d'aquesta situació, l'accés a la terra s'ha convertit, juntament amb els baixos preus del producte agrari, en l'impediment principal per a la incorporació de nous integrants al sector, que garanteixin el relleu generacional i la viabilitat de petites i mitjanes explotacions (Hebinck, 2018; Van der Ploeg, 2018; Horst i Gwin, 2018; Monllor, 2013; Bernstein, 2001; Sevilla-Guzmán, 2012).

Sota aquest context, aquest article revisa els canvis que han tingut lloc en els significats de la terra que han acompanyat les transformacions agràries en els processos de desagrarització global. Alhora, l'article pretén explorar les respostes simultànies a aquesta situació en clau de programes i projectes de reagrarització i d'accés a la terra dirigits a fer front, des de la proximitat, a la situació de crisi multidimensional dels sistemes agraris locals. 


\section{La desagrarització i la terra}

Com a resultat de la modernització agrària, el paper de la terra en la reproducció social ha perdut centralitat sota una nova interrelació entre agricultura, natura i localitat (Van der Ploeg, 2018). D'aquesta manera la terra s'ha deslligat de les organitzacions fundades en la família, el veïnat, el treball o el poble (Polanyi, 1989), s'ha separat del tot orgànic del qual formava part i s'ha evidenciat que, a banda d'una realitat material, la terra, com qualsevol altre recurs natural, esdevé una construcció social modelada per factors culturals, històrics, institucionals i biofísics que reflecteixen les relacions de propietat, poder i competència (Elden, 2010; Hubacek i Van den Bergh, 2006). Parallelament, la desagrarització ha generat unes condicions socials, físiques i materials que impossibiliten la reproducció dels mitjans de subsistència agraris i dependents de la terra, manifestades en canvis ocupacionals i en la marginalització de les petites i mitjanes explotacions (Hebinck, 2018) que van veure com les seves estratègies de producció i reproducció en clau pagesa es van mercantilitzar juntament amb els productes agrícoles, la terra, els instruments de producció i la força de treball (Bernstein, 2017).

D'aquesta manera, una bona part de la pagesia abandona l'activitat agrària com a activitat productiva principal i diversifica les estratègies productives i reproductives en un context en què el capitalisme subministra les bases materials de l'existència i domina totes les condicions de reproducció (Hebinck, 2018; Corbelle i Crecente, 2008; Comas d'Argemir, 1998). Així, amb la desagrarització, la migració rural-urbana pren força i s'erosiona la racionalitat pagesa, caracteritzada per una doble naturalesa d'unitat econòmica i familiar al voltant de la terra (Aguilar, 2014; Chayanov, 1925) que perd part de la dimensió política, social i productiva (Polanyi, 1989; Arnalte et alii, 2012).

En aquest context, amb la desfeta de les societats agràries, l'abandonament de la terra és una estratègia fortament estesa des de diverses geografies per donar resposta a les pressions de la modernització (Corbelle i Crecente, 2018; Ustaoglu i Collier, 2018; Pointereau et alii, 2008). Aquests processos d'abandonament es troben condicionats per situacions multidimensionals i sinèrgiques característiques de la desagrarització (Usta- 
oglu i Collier, 2018; Pointereau et alii, 2008) i venen marcats per la manca de viabilitat econòmica de les explotacions (Bernstein, 2001; Terres et alii, 2013); la presència de terres amb males qualitats agronòmiques, aïllades, o de difícil mecanització; l'envelliment, el despoblament i la manca de relleu generacional (Baldock et alii, 1996); la dependència d'ajuts públics, o els desequilibris econòmics entre els diversos sectors productius (Ustaoglu i Collier, 2018; Pointereau et alii, 2008; Terres et alii, 2013; Corbelle i Crecente, 2008).

Si bé l'abandonament de la terra suposa una estratègia d'adaptació al context de la desagrarització, també suposa una reducció en la disponibilitat de terres productives a causa dels fenòmens de reforestació, erosió i desertificació, entre altres processos de canvi en les cobertes del sòl (Corbelle i Crecente, 2008). D'aquesta manera, l'abandonament actuaria en sinergia amb la concentració de terres en mans d'altres generacions o la tinença de terres per part de complexos agroindustrials (Kay, 2018; Gilfoy, 2015) que també limitarien la disponibilitat del recurs.

En l'actualitat, a més, el desequilibri entre sectors productius i la pressió urbanística, especialment en zones periurbanes, genera mercats de la terra descompensats (Hubacek i Van den Bergh, 2006) on l'accés a la terra és en bona part determinat per qüestions de classe (Kay 2018; Bernstein 2017; Harvey 2005). Aquests fets, determinants en la negació de l'accés a la terra juntament amb les baixes rendes agràries i el desinterès general en el sector agrari (Monllor, 2013; Leavy i Hossain, 2014), dificulten conjuntament l'entrada de nous agricultors als sistemes agraris locals.

Partint d'aquest problema, entitats com Manos en la Tierra (2016), Vía Campesina, (2018), l'Agrupament per la Innovació Agrària a Europa (Comissió Europea, 2016), la FAO (2006), juntament amb nombrosos acadèmics com Hebinck (2018), Horst i Gwin (2018), Bernstein (2001), Monllor (2013) o Sevilla-Guzmán (2012), identifiquen l'accés a la terra com un dels problemes principals en la incorporació a l'activitat agrària. En aquest sentit, el cost econòmic de la terra, l'adequació de la terra al projecte productiu i la disponibilitat i seguretat sota un règim concret de tinença constitueixen les barreres principals d'accés (Horst i Gwin, 2018). 
Els bancs de terres (a partir d'ara, BdT) són una de les respostes que tant les administracions públiques com els agents privats han donat als reptes de l'abandonament i l'accés a la terra des de diverses escales (Corbelle i Crecente, 2008; Soler i Fernández, 2015; Andrés, 2014; Beesley i Ramsay, 2009). Aquestes eines funcionen sota lògiques molt diferenciades a diferents contextos i compten avui en dia amb una certa tradició a Europa, com són els casos de França, Holanda o Alemanya (Van Dijk i Kopeva, 2006). L'objectiu comú a tots els BdT a través d'actuacions amb més o menys caràcter estructural és el de facilitar l'accés a la terra en contextos de baixa disponibilitat de terres i abandonament per tal de garantir la viabilitat de les explotacions agràries i permetre la incorporació de nous integrants al sector.

En aquest sentit, la majoria de BdT s'enfoquen cap a la identificació de terres disponibles per a la producció i la mediació entre els propietaris i les persones que hi volen accedir: en el cas de Biscaia, l'administració adopta un rol de promoció i mediació en la transferència de terres de titularitat pública i privada per al desenvolupament de l'agricultura ecològica a través de contractes d'arrendament o cessió (Cruz, 2016). En el d'Astúries, l'administració ofereix contractes d'arrendament arran de plans de prejubilació en el sector agrari promoguts per la UE des dels anys noranta (Soler i Fernández, 2015; Rubio, 2010). A Galícia, l'administració autonòmica esdevé una de les parts en els contractes de cessió o arrendament de les terres que promociona, de manera que els que accedeixen a la terra ho fan a través d'un contracte amb un ens públic (Soler i Fernández, 2015).

En els casos dels BdT municipals i supramunicipals a Catalunya, l'administració pren el rol d'intermediari o dinamitzador del mercat de terres mentre que alhora facilita assessorament legal respecte a la seguretat dels contractes agraris que es generin entre particulars fruit de la mediació pública. Amb aquestes premisses, a Catalunya existeixen diferents $\mathrm{BdT}$ que elaboren bases de dades públiques sobre finques abandonades o properes al cessament de l'activitat i a mateix temps recullen la informació de persones o entitats collectives que cerquen terra amb l'objectiu de posar en contacte propietaris de terres en desús amb demandants que busquen tenir-hi accés. Així, a través dels agents públics, propietaris i de- 
mandants poden arribar a una entesa que culmini amb la signatura d'un contracte de cessió de la terra, arrendament o masoveria, entre d'altres, per evitar o revertir situacions d'abandonament i manca d'accés a la terra.

Havent exposat els impactes de la desagrarització sobre l'abandonament i l'accés a la terra, així com les línies d'actuació generals dels BdT, l'objectiu d'aquest article és el d'aprofundir en la transformació dels significats socials i culturals de la terra i del seu accés al llarg dels processos de desagrarització i reagrarització (Hebinck, 2018) en un indret de l'Europa mediterrània: el Camp de Tarragona. També es pretén explorar les estratègies i imaginaris sobre la terra que han seguit persones tant propietàries com demandants de terra que es troben vinculades a un $\mathrm{BdT}$ supramunicipal en aquest territori. Finalment, s'avaluarà el paper del $\mathrm{BdT}$ com a programa de reagrarització en la seva tasca de facilitació de l'accés a la terra.

\section{Cas d'estudi: el Camp de Tarragona i el Banc de Terres del Baix Camp}

Les desigualtats entre sectors productius al Camp de Tarragona durant els darrers 50 anys han impulsat lògiques de desequilibri en la matriu territorial, que han fomentat un desenvolupament dual entre els usos i les cobertes del sòl a l'interior del Camp, tradicionalment lligat al sector primari, i al litoral, caracteritzat per la urbanització i vinculat al turisme i la indústria (Muro, 2018).

Com que no s'ha publicat encara el Cens Agrari de Catalunya corresponent a l'any 2019, d'acord amb les dades disponibles de l'últim cens elaborat l'any 2009 (Idescat, 2012a) es pot veure com al Camp de Tarragona el nombre d'explotacions agràries va disminuir a menys de la meitat en menys de 30 anys, ja que el 1982 hi havia un total de 21.070 explotacions, mentre que el 2009 la xifra cau fins a les 9.403. Pel que fa a la terra, la superfície agrària utilitzada (SAU) va augmentar de les 6,41 ha per explotació el 1982 fins a les gairebé 9 ha per explotació el 2009. Tal com succeeix a la resta del nord global, el nombre d'explotacions disminueix dràsticament i augmenten la superfície, una conseqüència del procés de 
concentració de terres indispensable per a la modernització. No obstant això, l'abandonament de terres es fa palès al territori i es presenta com un dels reptes més greus del sector agrari, ja que la SAU total es va reduir al Camp de Tarragona més del 32\% entre el 1982 i el 2009. ${ }^{1}$

D'altra banda, les dades macroestadístiques reflecteixen que l'any 2009 ja hi havia una forta incidència de l'envelliment i la masculinització del sector, perquè dels 9.403 caps d'explotació al territori gairebé el 29\% té més de 55 anys i més d'un 33\% en té més de 65.

A partir d'aquestes dades, s'intueixen unes trajectòries encara més agudes que les seguides pel conjunt de Catalunya en els últims anys, en què, segons dades de l'Idescat (2017), el nombre d'explotacions agrícoles entre els anys 1993 i 2016 va disminuir entorn d'un 25\%, mentre que la SAU a Catalunya va caure gairebé un $26 \%$. Seguint aquests processos de transformació de la terra i dels sectors laborals, actualment només un 1,5\% de la població activa de Catalunya es dedica al sector agrari (Idescat, 2020).

Sota aquest context, el Banc de Terres del Baix Camp neix l'any 2017 amb l'objectiu de combatre els desequilibris estructurals del sector agrari i facilitar l'accés a la terra a la comarca del Baix Camp. ${ }^{2}$ Està gestionat pel Consell Comarcal del Baix Camp i és un servei públic de mediació entre propietaris i demandants de terres, de manera que posa en contacte propietaris que volen cedir o arrendar les seves terres i persones que volen introduir-se en el sector agrari o bé volen ampliar la superfície productiva de la seva explotació. D’aquesta manera, el BdT es troba inserit dins el Pla d'acció integral i sostenible del Baix Camp (a partir d'ara, PAIS Agrari), que, a través de diferents mesures complementàries, pretén revitalitzar el sector agrari de la comarca, capgirar la manca de relleu generacional i enfortir la producció sostenible i la valoració dels productes agraris al mercat, per tal d'intentar revertir la situació d'abandonament de la terra i d'èxode rural.

1 L'any 1982 hi havia 121.806 ha cultivades, mentre que el 2009 l'extensió de cultius decau fins a les 82.826 ha.

2 El BdT del Baix Camp actua a escala comarcal. No obstant això, la seva tasca s'ha caracteritzat en el context del Camp de Tarragona, entenent que els principals reptes del sector agrari comarcal són representatius i obeeixen a les mateixes lògiques d'aquesta delimitació territorial més àmplia. 
El BdT opera a través d'un lloc web amb informació qualitativa, quantitativa i cartogràfica sobre les finques, de manera que cada usuari té accés obert a la informació sobre el perfil de les finques en oferta i el perfil dels demandants de terra. En cas que els interessos encaixin, poden arribar a una entesa a través de la figura del tècnic del BdT. D’aquesta manera s'ofereix un servei d'intermediació gratuït que pot conduir a la signatura del corresponent contracte d'arrendament, cessió o masoveria sota criteris d'horitzontalitat i preus justos. També es facilita un acompanyament en l'àmbit jurídic, estratègic i tècnic enfocat a garantir la seguretat jurídica del contracte agrari i assegurar l'inici i el sosteniment de les explotacions sota criteris de sostenibilitat ambiental, social i econòmica (Consell Comarcal del Baix Camp, 2019).

\section{Metodologia}

Per donar resposta als objectius, s'ha utilitzat el mètode etnogràfic que ha permès un apropament empíric a la realitat microsocial al voltant del BdT del Baix Camp i ha facilitat la interpretació d'accions, valors, discursos, creences i maneres de viure de les persones respecte a la terra sota les cultures agràries que imperen al Camp de Tarragona (Soronellas i Casal, 2017). Així, s'ha abordat l'estudi de la terra i els imaginaris sobre el valor i accés des d'una perspectiva èmica, que reflecteix la comprensió de la realitat i les seves trajectòries des de l'imaginari dels mateixos actors que en són protagonistes.

El treball de camp es va realitzar entre els mesos de gener i maig de 2019. Les tècniques de recollida d'informació van ser l'observació participativa a través d'estades intensives al camp i entrevistes en profunditat. D'altra banda, la informació de caire quantitatiu ha estat obtinguda a través del buidatge de registres i censos estadístics facilitats per l'administració.

Les sessions d'observació van dur-se a terme assistint, i participant-hi, a les sessions de planificació del Pla Estratègic PAIS Agrari Baix Camp entre els mesos de gener i març de 2019. Les sessions van prendre la forma de debat centrat en el disseny d'accions i mesures per fer front als principals reptes del sector agrari de la comarca, diagnosticats 
prèviament. Hi van participar actors relacionats amb el sistema agroalimentari del Baix Camp de perfils socials heterogenis: petits agricultors, membres de cooperatives agràries, propietaris de terra, demandants de terra, agents territorials, agents d'ocupació o entitats de l'economia social, entre d'altres. Durant aquestes sessions, l'investigador va interactuar de manera horitzontal amb les persones presents a les reunions, tot participant en els debats, fet que ha permès la recollecció de dades de manera sistemàtica i no intrusiva sobre el posicionament relacional dels diferents actors o els discursos imperants sobre la terra, el BdT i els canvis en el sector agrari.

D'altra banda, es van realitzar entrevistes en profunditat entre els mesos de març i maig de 2019 que pretenien copsar els discursos de diferents actors vinculats d'una manera o altra amb el BdT. Per tal de comptar amb un discurs coral, la mostra d'informants es va seleccionar a partir de l'observació participativa en les jornades de planificació del PAIS Agrari i en collaboració amb el servei del BdT del Baix Camp, tenint en compte la diversitat de perfils quant al tipus de relació dels subjectes amb el recurs de la terra per assegurar una certa heterogeneïtat discursiva. Així, la mostra es compon de propietaris de terres inscrits al BdT com a oferidors, demandants de terra (procedents del sector agrari o nouvinguts) i agents territorials situats a l'òrbita de treball del BdT.

\section{Resultats i discussió}

\subsection{La terra i les transformacions agràries}

Tots els informants que visqueren el passat agrari del Camp de Tarragona, ja siguin demandants de terres, oferidors o agents territorials, s'han referit a la crisi dels preus de l'avellana dels anys vuitanta com a fenomen accelerador de l'abandonament de terres i de la desprofessionalització del sector agrari. L'atzucac entre els elevats costos de producció fruit de la modernització i uns preus de producte baixos com a resposta a la competència internacional va suposar el punt d'inflexió en la desintegració de la racionalitat pagesa al Camp de Tarragona. Arran de l'entrada de l'Estat espanyol al mercat comú de la UE, la terra amb què les unitats producti- 
ves comptaven fins aleshores deixa de ser suficient per assegurar la reproducció social. Com a conseqüència, es va produir una diversificació de les estratègies reproductives que va accelerar la pèrdua de vigència de la terra per sostenir un projecte professional: «Amb els avis, si feies 100 sacs d'avellanes et mantenies per a l'any, com si diguéssim; després l'avellana, amb els meus pares, va baixar molt de preu i ja no treus la producció que has de treure, i jo, ara, hi he de posar quartos» (O. F., propietària, oferidora de terres, 52 anys).

Una cosa semblant passà a altres indrets de la península Ibèrica com a Galícia, on la crisi agrària i l'abandonament de terres es fa notable a partir dels anys vuitanta, un altre cop a partir de l'entrada d'Espanya al mercat comú europeu (Corbelle i Crecente, 2008). Així, al Camp de Tarragona, a partir dels vuitanta les estratègies reproductives passen per: diversificar els ingressos amb feines al sector industrial $i$ als serveis; vendre la terra o treballar-la a temps parcial, o reorientar els conreus per adaptar-se a les exigències del mercat.

Amb el pas del temps, els actuals propietaris de la terra que disposen de rendes externes al sector agrari enfronten les fluctuacions de preus disminuint la implicació en la gestió de la terra. La duresa de la feina amb un baix grau de mecanització, la dedicació més enllà de la jornada laboral, el baix preu dels productes agraris i l'absència d'un pagès professional (com en temps de la generació dels pares) han provocat l'abandonament o, en el millor dels casos, la cessió i l'arrendament de la terra com a úniques alternatives per conservar el patrimoni familiar sense patir despeses econòmiques importants.

Quan ja em van dir el preu que portava [l'avellana] aquest any dic: sí, home! A més, vaig de genolls, encara amb el rasclet allí plegant-les... Vaig dir: a veure, una cosa és fer-ho per amor a l'art i l'altra és anar allí i deixar-te la pell per no res. No em surt a compte, em surt més a compte comprar les avellanes si en tinc ganes de menjar-ne i ja està. (O. F., propietària, oferidora de terres, 52 anys)

El relat de l'Olga, que va heretar camps d'avellaner i olivera dels seus pares i ha continuat gestionant la terra durant anys a temps parcial, reflecteix com la terra segueix present sobretot en l'àmbit simbòlic en l'es- 
tratègia de reproducció familiar, però també com el seu rol productiu central s'ha anat diluint a través d'estratègies diferents: la venda de la terra, la migració cap a les ciutats o l'alternança del treball al camp amb altres sectors laborals.

En aquesta línia, els propietaris que participen en el BdT del Baix Camp entenen la terra com la base sobre la qual han articulat les tasques productives i reproductives des de la infantesa. El treball agrari ha estat per a ells una activitat que involucrava les estones lliures de tota la unitat familiar i la terra, el recurs on es desplegaven les relacions socials, la producció econòmica, els aprenentatges intergeneracionals, les complicitats, les opressions, els afectes, i la transmissió de valors i de coneixement. Els pares dels informants i ells mateixos resignifiquen la terra, la qual deixa de ser el centre de les estratègies familiars de reproducció per passar a tenir un rol secundari molt més lligat als valors de preservació de la propietat, el patrimoni familiar, la identitat i la memòria (Duesberg, 2017; Arnalte et alii, 2012):

Els valors en els que m'he educat són pròpiament els de la terra i els he après a la terra. Ha sigut un element vertebrador familiar com a espai, com a paisatge, com a moltes coses, però també hi ha aquesta cosa del treball, de la família... (L. P., pagès professional, demandant de terres, 44 anys)

Després que els seus avis visquessin de la terra, i que diferents masovers l'hagin treballada durant la generació dels seus pares, el Llorenç torna a treballar professionalment la terra de la seva família i reflecteix la importància de la socialització amb la terra i les tasques agràries en el desenvolupament del lligam amb la terra (Duesberg, 2017), i com els valors apresos a la terra han estat decisius per conformar la manera en què ara perceben el camp i com han decidit relacionar-s'hi. Amb aquests valors transmesos pels seus avis i pares, les persones propietàries de terres projecten la seva imatge de com ha de ser la terra: un paisatge «cuidat», amb una terra treballada i el paisatge «net i clar», sense herba ni arbustos, amb les oliveres «esporgades» $\mathrm{i}$ amb els marges «ben arreglats». Alhora, els informants que s'han dedicat parcialment a l'agricultura admeten: «Si no t'hi jugues el sou, aquest treball és tan sacrificat i poc valorat que no- 
més el pots fer pels records i per l'estimació a la terra» (A. B., propietari, oferidor de terres, 40 anys).

La cura cap a la terra i la duresa de la feina connecta amb una altra idea del relat dels informants: el desprestigi de treballar la terra. Aquesta manca de reconeixement social al Camp de Tarragona s'identifica com una de les raons principals de l'abandonament de la terra i la manca de relleu que agreuja la problemàtica de la terra i les baixes rendes agràries. En aquest aspecte, tal com diuen Alonso et alii (1991) o Servolin (1977): ser pagès era un desprestigi i es relacionava amb la classe social més baixa, una manera de viure ancestral $i$ anacrònica, molt sacrificada, amb poques comoditats i una economia de subsistència i no-acumulació. S'hi refereix un dels tècnics que collabora estretament amb el BdT: «Lagricultura no és una feina facil. És l'últim esglaó social. Un pagès és un mal educat, un brut, un llord, un ignorant... això encara, l'estereotip hi és» (X. G., tècnic de cooperativa agrícola, 43 anys).

També, tal com esmenta Van der Ploeg (2018) en el marc d'una visió dicotòmica del camp, els pagesos i el seu vincle emocional amb la terra són percebuts com a antagonistes del progrés i de l'eficiència que suposa la modernització. Alhora, d'acord amb Pointereau et alii (2018), l'arribada dels valors urbans al món rural suposa un rebuig per part de la pagesia de la subalteritat i la subsistència amb què han estat categoritzats des de fora. L'oposició d'aquest estil de vida amb els valors de la modernització agrària i l'acumulació accentua la difusió d'un imaginari collectiu que rebutja la terra com a recurs productiu i reproductiu perquè ja no es necessita, com tampoc no es necessita les persones que se'n cuiden. Obeint aquesta lògica, les subjectivitats s'individualitzen, la terra es cosifica i es converteix en un bé mercantilitzat a través de contractes privats, mentre se'n dificulta l'accés i deixa de ser percebuda com a factor productiu i reproductiu compartit (Arnalte et alii, 2012; Paniagua, 2008; Polanyi, 1989).

\subsection{La nova pagesia i l'accés a la terra}

Els informants demandants de terra al BdT són neorurals o descendents de pagesos i agricultors a temps parcial que plantegen discursos semblants pel que fa a l'orientació dels seus projectes: volen en gran manera 
accedir a la terra i treballar-la des d'estratègies ecològiques o agroecològiques i atorgar un rol central a la terra en l'estratègia productiva, i diferenciar-se de la generació anterior, que havia entrat en una relació de dependència respecte a unes entrades i una tecnologia que s'escapava del seu control.

Hi ha un conflicte generacional entre aquesta generació i la nostra. Clar, perquè tu vas amb un projecte no només agronòmic, sinó agroecològic i, clar, xoques completament amb ells [...] ara toca desaprendre molt tot això [...] que ells entenguin que el seu model ha fracassat. (L. P., pagès professional, demandant de terres, 44 anys)

Com reflecteix el discurs del Llorenç, amb un model agrari que trenca respecte a la generació anterior, els demandants de terres conformen un nou paradigma agrosocial (Van der Ploeg, 2018; Monllor, 2013) i en cap cas no postulen retrobar en la terra un primitivisme o autenticitat del passat, sinó que tenen una clara intencionalitat de reconduir la producció d'aliments en contraposició al model agroindustrial amb la voluntat de recuperar la terra com un recurs productiu central a partir de diverses accions: una producció petita amb els factors productius sota control; la recuperació d'elements essencials de les cultures i pràctiques agràries locals; alts coneixements tècnics en agronomia i gestió de sòls; una important posada en valor del producte ecològic, de proximitat i d'alta qualitat; circuits de comercialització curts, i la creació de sinergies amb altres productors de l'àmbit local sota criteris de sostenibilitat ecològica i justícia social:

Es tracta d'intentar donar una miqueta de vida sempre des del punt de vista ecològic, de sostenibilitat, d'augmentar la biodiversitat, una economia social també, buscar el petit productor també [...] i intentar invertir la tendència de que tot quedarà absorbit per grans empreses. (X. G., tècnic de cooperativa agrària, 43 anys)

Les estratègies de les persones que s'han inscrit al BdT com a demandants de terres volen recuperar certes traces d'una racionalitat pagesa que es va perdre en la generació anterior i defensen la necessitat que les explotacions siguin capaces de subsistir comptant principalment amb la 
producció agrària. Els seus discursos, però, no menystenen el paper de la diversificació d'activitats en l'estratègia reproductiva de les explotacions, ni les sinergies amb la producció de serveis ambientals sota el paradigma de l'ambientalització de l'agricultura (Aguilar, 2014). Els informants formen part del que es coneix com a nova pagesia: un grup social heterogeni que es caracteritza per una nova manera d'entendre i viure l'activitat agrària des de la sostenibilitat ecològica, social i econòmica, en contraposició a l'agroindústria i partint d'una vinculació amb la terra basada en la recuperació del coneixement local, la presa de control sobre els factors productius i el guany d'autonomia respecte als mercats i les polítiques públiques (Monllor, 2013; Öztürk et alii, 2018; Van der Ploeg, 2018). Els seus projectes configuren un nou context de reagrarització que conviu amb la desagrarització i que esdevé una resposta local a partir d'un apropament a les pràctiques i estratègies associades a les cultures agràries locals.

Aquest acostament a la terra hibrida diferents tipus de coneixement i imaginaris de diferents generacions i sistemes agraris, la qual cosa genera un important impacte en el món rural, en les relacions rural-urbà i en l'estructuració de les pràctiques i dinàmiques agrícoles (Van der Ploeg, 2018). Els projectes de reagrarització de la nova pagesia actuen com una resposta local al context global de desagrarització. Aquesta contestació, si bé no és nova, sí que ho és pel que fa a la magnitud que agafa en el present. En aquest sentit, diversos autors com Servolin (1977), Altieri i Nichols (2010), Sevilla-Guzmán (2012) i López (2012) recorden que la transició cap a formes globalitzades de producció ha esdevingut un procés que mai no ha estat unidireccional, sinó que ha generat moviments d'hibridació entre la cultura moderna o urbana-agroindustrial i les diferents formes subalternes de pagesia que ja existien. Aquests enunciats, coincidint amb l'heterogeneïtat de la pagesia i dels seus processos de mercantilització, ha generat un espai liminar on s'emmarca la nova pagesia que encarna processos de reagrarització local en contextos globals de desagrarització.

Entre aquests actors de la reagrarització, en Xavier exposa que les actuacions per part dels estats i les polítiques agràries no han abordat el problema central de la pagesia: la manca de reconeixement. Aquesta si- 
tuació, que, d'acord amb l'informant, ha aprofundit la crisi de les petites i mitjanes explotacions, ha quedat sense resposta a causa d'una manca d'estructura interna i d'intercooperació en el sector:

No es va al rovell de l'ou, que és que la pagesia té un valor intrínsec en si [...]. Aquí hi ha un nyap de 40 anys i després un altre nyap de 40 anys més i això pesa al subconscient de la gent [...] i on falla és a l'articulació, a la collaboració [...]. Llavors hi ha les contrarèpliques que arriba un moment que se saturen, que no són eficients: això no va bé però no hi ha una alternativa. (X. G., tècnic de cooperativa agrària, 43 anys)

Tal com diu l'informant, d'acord amb Requena i Mora et alii, (2017) i Alonso et alii, (1991), la manca d'estructura comuna impedeix l'establiment de vincles orgànics potents $i$ individualitza l'agricultor sobre l'autoreferència i la seva terra, de manera que els sentiments de classe tenen poques oportunitats per desenvolupar-se en comparació amb altres collectius i àmbits productius. Sota aquest context de desarticulació, la política agrària comuna (PAC) és percebuda per l'informant com l'element accelerador de la mercantilització de la terra i legitimador del debilitament de la pagesia com a grup socioeconòmicament heterogeni: «La PAC ha estat la morfina d'una generació [...]; per molt que vosaltres hagueu reivindicat i feu un acte d'enervació en algun moment determinat, no heu arreglat res. Hem interioritzat que els amos són els altres» (X. G., tècnic de cooperativa agrària, 43 anys).

D'altra banda, Aguilar (2014) i Soronellas i Bodoque (2016) sostenen sota aquesta perspectiva que la PAC, a través dels seus ajustos en el temps, ha consolidat la interrelació global entre agricultura i societat i ha acabat transformant els espais rurals des d'instàncies supranacionals; va plantejar en una primera etapa una agricultura industrialitzada i enfocada a l'increment de la productivitat, per després prendre l'estratègia d'estimular l'agricultura multiserveis com a alternativa per palliar la crisi demogràfica i reproductiva de les àrees rurals. També, tal com esmenten Ustaoglu i Collier (2018); Pointereau et alii (2008) i Terres et alii (2013), aquests ajuts poden despertar l'interès especulatiu per la terra i assentar l'estructura de la propietat, atribuint una renda directa a la terra, que de nou cobraria valor de mercat més enllà del valor productiu. 
En aquest aspecte, l'Óscar, un jove participant en les sessions de planificació del PAIS Agrari, apunta que aquests ajuts actuen amb paternalisme, $i$ allunyen la pagesia de la terra i dels seus projectes productius:

La subvenció té un paper molt important perquè molts s'hi fiquen simplement per cobrar les subvencions perquè amb la subvenció ja poden viure mes enllà d'avaluar el projecte [...]; ell sap que s'agafarà $8.000 \mathrm{eu-}$ ros de la subvenció de la terra, una altra per a no sé què i fa comptes amb les subvencions, no amb l'avellana. No fa el compte amb la llet que produeix, ell fa comptes amb que la cabra és raça autòctona. (Óscar, pagès professional, 35 anys)

Pel que fa a l'accés a la terra, el discurs dels informants reflecteix un sistema d'accés a la terra desigual, ja que, a banda de l'abandonament, la baixa disponibilitat i els preus marcats per l'especulació, el caràcter local del mercat de terres dificulta l'accés a les persones de fora. Aquest fet és especialment rellevant per a la nova pagesia vinculada al $\mathrm{BdT}$, perquè molts són neorurals.

LAnna va aterrar al Baix Camp fa 5 anys amb la seva família. Mentre ella treballa al sector públic, la seva parella lidera un projecte ramader. Ella explica el tancament de la terra per a forans de la manera següent:

Has de conèixer a la persona, el marxant de terres, que coneix o que pot conèixer... i després en funció d'això i de com t'hi entens... clar, vas perdut i fas moltes voltes i, a més, si ets de fora ho tens difícil perquè no tens el veí que li puguis preguntar, perquè no ets veí de ning... D’entra$\mathrm{da}$, doncs, la transparència falta perquè no coneixes... (A. M., neorural, tècnica agrària)

També el Manel, agent d'Ocupació i Desenvolupament Local, esmenta que abans de l'existència del BdT l'estratègia d'accés a la terra consistia a apropar-se a alguna persona que formés part de la xarxa d'actors locals capaç de generar confiança a un propietari: «Havies de caure-li bé a algú d'algun poble perquè aquesta persona donés veus i t'avalés d'alguna manera perquè et presentés a un propietari amb el qual entendre-t'hi» (Manel, tècnic AODL, 40 anys). 
En aquest aspecte, els informants troben en el BdT una fórmula per augmentar la seva superfície productiva, però també per combatre les dificultats d'accés a la terra per a gent amb poca capacitat d'endeutament i de fora de l'àmbit local, que sovint combinen amb altres estratègies com la recerca autònoma de terres, el contacte amb ajuntaments o altres administracions locals o la penjada de cartells explicant el seu projecte productiu i la seva necessitat d'accedir a la terra.

\subsection{El banc de terres com a programa de reagrarització}

Tot i la creació recent, el BdT del Baix Camp es comença a consolidar com a programa de reagrarització i ha esdevingut el BdT supramunicipal de referència a Catalunya. Són diversos els projectes de BdT que han sorgit arreu del principat seguint una trajectòria similar a la del Baix Camp i que avui es troben en els primers estadis d'activitat o encara en fase de planificació, com el BdT del Priorat, el de les Terres de l'Ebre, el del Parc Rural de Montserrat o el de la Xarxa per la Sobirania Alimentària de la Catalunya Central.

Dels 57 demandants de terra del BdT del Baix Camp, 47 (83\%) plantegen projectes agraris d'orientació ecològica. Majoritàriament, són persones joves que encaixarien amb el paradigma de la nova pagesia (Van der Ploeg, 2018; Öztürk et alii, 2018; Monllor, 2013), amb una forta presència de neorurals. Així, un gruix significatiu de demandants de terres compten amb un potencial transformador important pel que fa a la realitat del sistema agrari del Camp de Tarragona a través d'un acostament a les cultures agràries locals, a l'agroecologia, a l'autonomia respecte als mercats globals i al control sobre la terra i la resta de factors productius. No obstant això, aquests líders o futurs líders de projectes locals de reagrarització són alhora els més mancats de les bases materials en forma de terres i capital necessaris per sostenir un projecte agrari professional. Especialment els forans, que es troben doblement perjudicats per la condició de joves, amb poca experiència i capacitat d'inversió i, a més, desconeixedors del mercat local de terres.

D'altra banda, només 10 demandants (17\%), generalment pagesos ja consolidats o en vies de consolidació, i, per tant, amb una certa infraes- 
tructura i capacitat d'endeutament, plantegen projectes de caire convencional o d'agricultura integrada.

Els propietaris que ofereixen terres a través del BdT se situen entre els 45 i 55 anys. Malgrat la idiosincràsia de cada situació, la majoria són propietaris recents, que han heretat la terra fa poc temps i tenen clar que no la gestionaran bé perquè no es volen dedicar al sector agrari, ni de manera professional ni parcial, o perquè les característiques de les finques no són agronòmicament òptimes i no encaixen en el seu model d'explotació. Sigui pel motiu que sigui, els oferidors de terra es mouen per valors que sobrepassen el benefici econòmic, generalment en zones no propenses a l'especulació. L'objectiu prioritari dels propietaris dins el BdT és «no deixar perdre la terra» $i$ «tenir la terra cuidada» com a part del llegat familiar i de la seva identitat; apellen al seu valor intrínsec i simbòlic, que es perdria en mans de l'abandonament, i, per tant, recorren a la necessitat de resistir-s'hi (Franquesa, 2018; Duesberg, 2017).

Una bona part dels propietaris té por de perdre la terra, entenent que perdre-la s'assimila a veure-la «bruta» i poc cuidada, amb «males herbes» i amb la presència de matolls i bosquines. És a dir, «perdre la terra» equival al fet que no sigui productiva o que sigui gestionada d'acord amb uns valors o pràctiques amb els quals no estan d'acord, sovint diferents dels de l'agricultura convencional que practicaren els seus pares. Així, s'espera en alguns casos que aquesta visió sobre l'estructura del paisatge agrari i els seus components estètics pugui entrar en conflicte amb el model agrari dels demandants de terra que plantegin formes de cultiu des de l'agroecologia, l'agricultura ecològica i l'agricultura regenerativa. És per aquest motiu que el procés de negociació i entesa sobre les pràctiques agràries, les infraestructures i altres components biofísics del paisatge, així com les cultures agràries que els usuaris del BdT posen de manifest, esdevé un punt imprescindible previ als acords entre propietaris i demandants de terra.

D’aquesta manera, els propietaris s'atansen al BdT per la confiança que els genera el servei, i saben que, si bé no obtindran els mateixos guanys econòmics que amb altres estratègies, tampoc no hi tindran despeses i, a més, s'asseguren que les finques siguin gestionades seguint uns paràme- 
tres acordats prèviament: «Ho vaig exposar i vaig dir: escolteu-me, mira, busquem una possibilitat, algo que es pugui fer perquè allò estigui net i no es perdi i llavors, com que sabia lo del Banc de Terres, ho vaig proposar i van dir que sí, perquè ho portin i no es perdi la terra» (O. F., propietària, oferidora de terra).

Els oferidors de terres al BdT són hereus d'una generació que ha participat d'un mercat de la terra tancat $i$ basat en lògiques de veïnatge i proximitat, de manera que l'oferta i demanda de terra productiva circulava dins una xarxa social agrària, acotada i geogràficament localitzada. A causa de la mida i de les necessitats de les explotacions, és habitual que, quan algun propietari es jubila, les seves terres siguin arrendades o venudes a l'explotació veïna, que cercarà ampliar la superfície productiva.

Aquesta lògica dels mercats de terra locals és la principal limitació que pot tenir el BdT d'acord amb alguns informants. Així, és possible que les finques agronòmicament òptimes, amb infraestructures de reg, ben situades i de dimensions més elevades quedin fora de l'accés de bona part de la nova pagesia perquè ja trobarien sortida dins de la xarxa agrària local i no arribarien a incloure's al BdT. Com diuen Ustaoglu i Collier (2018) i Pointereau et alii (2008), són les finques marginals, més petites, periferiques, de secà o amb el sòl degradat les que no troben sortida al mercat local i sovint estan sentenciades a l'abandonament. És probable, doncs, que siguin sobretot aquestes les que s'acabin incorporant al BdT. Així, un repte identificat pels informants seria augmentar la superfície de terres en oferta, així com l'heterogeneïtat, factor limitant en projectes similars d'intermediació de terres (Cruz, 2016).

En aquest sentit, d'acord amb els propietaris i agents territorials que han percebut aquest risc, la situació de desequilibri entre oferta i demanda de terra es podria palliar si el BdT incorporés una estratègia prospectiva, de manera que es poguessin identificar les propietats (o finques) susceptibles de ser incorporades al registre de terres abans que els propietaris s'interessessin per l'eina del BdT, a través de la cerca in situ de terres abandonades o properes al desús.

Des del BdT s'entén que la confiança és l'element clau que cal treballar per tal de millorar l'oferta de terres i l'apropament a nous propietaris 
en un futur, sobretot a través del boca-orella. I és que propietaris i demandants de terra relacionen la consolidació del projecte del BdT amb la proximitat i la confiança en la persona que gestiona el servei, coneguda i valorada a la comarca més enllà de la seva tasca professional actual. La figura del tècnic esdevé un dels factors clau que expliquen que tant persones demandants com oferidores s'interessin pel projecte del BdT. D'altra banda, l'abast geogràfic del servei centrat en la comarca del Baix Camp és prou proper per assegurar les relacions de proximitat entre el personal tècnic i els propietaris, de manera que els tràmits amb l'administració que podrien generar desconfiança es poden fer de manera presencial a través del tècnic, que actua com a persona de referència i enllaç entre propietaris i demandants. Així, la presència de l'administració en la negociació i signatura del contracte agrari esdevé un motiu de seguretat i no de desconfiança. Aquest fet és remarcable, ja que el BdT és capaç de reproduir la proximitat i la confiança de les dinàmiques locals del sector agrari per tal de superar la desconfiança històrica de la pagesia envers una administració que ha contribuït a la mercantilització i la posició subalterna respecte a altres sectors econòmics i socials (Requena i Mora et alii, 2017; Bernstein, 2001; Alonso et alii, 1991; Servolin, 1977).

El BdT del Baix Camp, en la seva tasca democratitzadora de l'accés a la terra, representa un exemple de com des de finals dels anys noranta les administracions locals i supramunicipals comencen a ser conscients dels beneficis econòmics, socials i ambientals que les petites explotacions de caire agroecològic comporten per als seus espais d'acció (Horst i Gwin, 2018). La reagrarització que encarna la nova pagesia genera ocupació al sector primari, garanteix el subministrament d'aliments ecològics i de proximitat mentre treballa per la prevenció de riscos ambientals com el canvi climàtic o el risc d'incendi sota una estratègia comuna enfocada a enfortir la resiliència del sistema socioecològic (Altieri i Nichols, 2010; Aguilar, 2014; Heatherington, 2011; Horst i Gwin, 2018; Soronellas, 2012).

Són justament les administracions locals i regionals les que juguen un rol decisiu a fer un ús just i inclusiu de la terra com a recurs (Comissió Europea, 2016; Manos en la Tierra, 2016). En aquest aspecte, els BdT com a projectes en consolidació tenen un paper rellevant com a iniciatives de 
reagrarització per transformar les condicions d'accés al recurs de la terra, democratitzar-lo i obrir el camí a la nova pagesia. D’aquesta manera, el BdT del Baix Camp pot esdevenir el pal de paller del procés de reagrarització al Camp de Tarragona des d'una nova cultura de la terra, del camp i de la ruralitat.

\section{Conclusions}

El Camp de Tarragona s'ha inserit en les lògiques globals d'expansió de l'economia de mercat i de desagrarització progressiva. En aquest context, l'agricultura a temps parcial que els pares dels informants van desenvolupar ha permès conservar el valor simbòlic i identitari de la terra al Camp de Tarragona, que s'ha transmès a la generació actual de propietaris a través de les estratègies de treball familiar. No obstant això, en un futur s'espera que entre les següents generacions, amb la pèrdua del treball familiar, de la socialització i del vincle directe amb la terra, el valor simbòlic i el sentiment de responsabilitat per tenir-ne cura acabaran desapareixent.

La percepció dicotòmica d'una agricultura moderna i eficient, amb grans explotacions tecnificades, enfrontada a una suposada pagesia anacrònica subjecta a lògiques de subsistència, ha desprestigiat les cultures agràries locals del Camp de Tarragona, el sector primari en general i les persones que s'hi dediquen. En aquest context, l'atzucac entre costos productius i preus dels productes agraris i el control de preus per part de l'agroindústria i les empreses comercialitzadores va suposar l'abandonament de l'activitat agrària com a principal estratègia productiva per part de la pagesia, la qual cosa va desembocar en l'abandonament d'una bona part de la terra agrícola.

Les polítiques públiques han estat el suport institucional bàsic per als processos de desagrarització i mercantilització de la terra. D’aquesta manera, la reagrarització i l'apropament a les estratègies de reproducció pageses al Camp de Tarragona s'insereixen en uns contextos globals de desagrarització postindustrial. L'etnografia duta a terme entorn del BdT evidencia que aquesta situació ha generat respostes divergents des de la localitat per part de la nova pagesia, que conjuga estratègies que contes- 
ten les lògiques de la modernització agrària en un context simultani de desagrarització i reagrarització.

Malgrat la significança d'aquestes trajectòries i el potencial de canvi pel sistema socioecològic, la reagrarització no és un procés generalitzat al Camp de Tarragona. Més aviat al contrari. En aquest sentit, és vital que les transformacions sobre la terra i les noves estratègies que proposen els projectes locals de la nova pagesia s'articulin amb unes polítiques públiques localitzades que els donin suport i siguin capaces de fer front als principals obstacles.

El paper del BdT despunta com a programa públic de reagrarització, ja que facilita l'accés a la terra i elimina, per tant, una de les principals barreres d'incorporació i viabilitat de l'activitat agrària. Aquest fet és especialment remarcable al Camp de Tarragona, perquè el BdT catalitza els projectes de la nova pagesia en una regió fortament pressionada per usos del sòl no agraris i per l'abandonament de terres marginals. A més, la iniciativa del BdT compta amb una important càrrega simbòlica, atès que des de la mateixa administració es pretén retornar la terra a la pagesia, el mitjà de producció fonamental i element definitori per excelllència del qual va ser desposseïda arran de la modernització agrària.

Els participants com a demandants de terra al BdT són persones joves i amb alta formació, poca capacitat d'endeutament i, sovint, de fora del territori que encarnen els valors de la nova pagesia. D'altra banda, els propietaris de terres abandonades o properes a l'abandonament que ofereixen les terres al BdT són en bona part hereus recents de terres que se situen entre els 45 i els 55 anys, i busquen mantenir el patrimoni familiar i el valor simbòlic d'una terra que, per la seva situació o característiques agronòmiques, difícilment tindria un valor de mercat important.

En aquest sentit, la confiança en l'administració pública i el control sobre la propietat i una gestió de la terra consensuada amb els demandants esdevé un fet de pes per als propietaris en la decisió d'incloure les seves terres al BdT. Per això s'ha mostrat important, primerament, la lògica del $\mathrm{BdT}$ com a simple mediador en els contractes agraris, de manera que la propietat i el poder de decisió sobre la terra continua estant en mans dels propietaris. En segon terme, l'escala del BdT i les persones a càrrec han 
esdevingut vitals per establir relacions de confiança i de proximitat que reprodueixen les relacions del mercat de terres característic de la cultura agrària local a través de l'entesa mútua i el tracte directe.

En un futur proper, caldria dedicar esforços a caracteritzar en profunditat els processos d'abandonament de la terra i els diferents models de $\mathrm{BdT}$ que hi intenten donar resposta, les estratègies adoptades, els seus reptes $\mathrm{i}$ les potencialitats pel que fa a la transformació del sistema agrari i socioecològic on s'insereixen. D'altra banda, caldria analitzar els plans i programes en què s'emmarquen els BdT i la coordinació amb marcs de governança a diverses escales per tal de fer front a les barreres estructurals del sector agrari sota la influència d'una creixent desagrarització i reagrarització.

\section{Bibliografia}

Aguilar, E. (2014). «Los nuevos escenarios rurales: de la agricultura a la mutifuncionalidad». Éndoxa: Series Filosóficas, 33: 73-98.

Alonso, L. E.; Arribas, J. M.; OrTí, A. (1991). «Evolución y perspectivas de la agricultura familiar: De «propietarios muy pobres» a «agricultores empresarios»». Política y Sociedad, 8: 35-70.

Altieri, M. A.; Nicholls, C. I. (2010). «Agroecología: Potenciando la agricultura campesina para revertir el hambre y la inseguridad alimentaria en el mundo». Revista de Economía Crítica, 10: 62-74.

ANDRÉs, G. (2014). «La implantació de bancs de terres: una solució a l'abandonament de les terres agrícoles?» Revista del Collegi Oficial d'Enginyers Tècnics Agrícoles i Perits Agrícoles de Catalunya, 18: 22-23.

Arnalte, E.; Baptista, F. O.; Garrabou, R. (2012). «Viejas y nuevas dimensiones de la cuestión de la tierra». Revista Española de Estudios Agrosociales y Pesqueros, 231: 11-35.

Baldock, D.; Beaufoy, G.; Brouwer, F.; Godeschalk, F. (1996). Farming at the Margins. Abandonment or redeployment of Agricultural Land in Europe. Londres / La Haia: Institute for European 80. Environmental Policy (IEEP) / Agricultural Economics Research Institute (LEI-DLO)

Beesley, K. B.; Ramsay, D. (2009). «Agricultural land preservation», a: International Encyclopedia of Human Geography, p. 65-69. 
Bernstein, H. (2001). ««The peasantry» in global capitalism: who, where and why?». Socialist Register: 25-52.

- (2017). «Political economy of agrarian change: Some key concepts and questions». History, Theory and Methodology of Sociological Research, 17(1): 7-18.

Chayanov, A. V. (1925). La organización de la unidad económica campesina. Buenos Aires: Ediciones Nueva Visión, 1985.

Comas d'Argemir, D. (1998). Antropología Económica. Barcelona: Ariel.

Comissió Europea (2016). Supporting access to land for farmers in Europe. Experiences and potential of local authorities. Disponible en línia. <https:// www.accesstoland.eu/IMG/pdf/a2l_handbook_local_authorities. pdf>. [Últim accés: 04/01/2020].

Consell Comarcal del Baix Camp (2019). Servei web del Banc de Terres del Baix Camp. Disponible en línia. <http://campviu.cat/>. [Últim accés: 04/01/2020].

Corbelle, R. E.; Crecente, M. R. (2008). «El abandono de tierras: concepto teórico y consecuencias». Revista Galega de Economía, 17(2): 1-15.

CRUZ, J. (2016). «Problemática de los centros de intermediación de tierras agrarias en espacios periurbanos. Discusión a partir del ejemplo vasco». Boletín de la Asociación de Geógrafos Españoles, 70: 149-168.

Duesberg, S.; Bogue, P.; Renwick, A. (2017). «Retirement farming or sustainable growth - land transfer choices for farmers without a successor». Land Use Policy, 61: 526-535.

Elden (2010). «Land, terrain, territory». Progress in Human Geography, 34(6): 799-817.

FAO (2006). Land access in the $21^{\text {st }}$ century: issues, trends, linkages and policy options. LSP Working Paper, 24.

Franduesa, J. (2018). «D'erms, pagesos i molins». Arxiu d'Etnografia de Catalunya, 18: 159-192.

Gilfoy, K. (2015). «Land grabbing and NGO advocacy in Liberia: a deconstruction of the "homogeneous community»". African Affairs, 114: 185-205.

HaRveY, D. (2005). A brief history of neoliberalism. Oxford: Oxford University Press. 
Hebinck, P. (2018). «De-/re-agrarianisation: global perspectives». Journal of Rural Studies, 61: 227-235.

Horst, M.; GwIN, L. (2018). «Land access for direct market food farmers in Oregon, USA». Journal of Rural Studies, 75: 594-611.

HubaceK, K.; VAN Den Bergh, J. (2006). «Changing concepts of «land» in econòmic theory: from single to multi-disciplinary approaches». Ecological Economics, 56: 5-27.

IdesCAT (2012a). Cens Agrari del Camp de Tarragona, 1982-2009. Disponible en línia. <http://www.idescat.cat/pub/?geo=at\%3AATo3\&id=censag>. [Últim accés: 24/04/2020].

- (2012b). Anuari Estadístic de Catalunya. Disponible en línia. <https:// www.idescat.cat/pub/?id=aec\&n=423>. [Últim accés: $24 / 04 / 2020$ ].

- (2017). Enquesta sobre l'estructura de les explotacions agràries de l'INE. Disponible en línia. <http://www.idescat.cat/pub/?id=expagr\&n=553>. [Últim accés: 24/04/2020].

- (2020). Població ocupada, per sectors d'activitat $i$ sexe. Disponible en línia. $<$ https:/www.idescat.cat/indicadors/?id=anuals\&n=10387>. [Últim accés: 24/04/2020].

$\mathrm{KAY}, \mathrm{S}$. (2018). Acaparamiento de tierras en Europa. Amsterdam:Transnational Institute / Hands On The Land.

Leavy, J.; Hossain, N. (2014). Who wants to farm? Youth aspirations, opportunities and rising food prices. Institute for Development Studies, University of Sussex.

López, D. (2012). «Hacia un modelo europeo de extensión rural agroecológica. Praxis participativas para la transición agroecológica. Un estudio de caso en Morata de Tajuña, Madrid». Universidad Internacional de Andalucía.

Manos en la Tierra (2016). Claves y propuestas para una politica de tierras responsable y sostenible en defensa de la soberanía alimentaria y por un mundo rural vivo. Disponible en línia. <https://cerai.org/wordpress/wp-content/ uploads/2016/04/28-04-2016-ManosenlaTierra-propuestas-cas. pdf 82>. [Últim accés: 04/01/2020].

Monllor, N. (2013). «La nova pagesia, vers un nou model agrosocial». Quaderns Agraris [Institució Catalana d'Estudis Agraris], 35: 7-24. 
Moyano, E.; Paniagua, A. (1998). «Agricultura, espacios rurales y medio ambiente». Revista Internacional de Sociología (RIS), 19-20: 127-152.

Muro, J. I. (2018). «La consolidació d'un paisatge urbà i el turisme a Tarragona». Arxiu d'Etnografia de Catalunya, 18: 193-219.

Murua, J. R.; Astorkiza, I.; Eguia, B. (2012). «Abandono e infrautilización del suelo agrario en la Cornisa Cantábrica: El caso del País Vasco». Revista Española de Estudios Agrosociales y Pesqueros, 231: 63-91.

ÖztÜrk, M.; Jongerden, J.; Hilton, A. (2018). «The (re)production of the new peasantry in Turkey». Journal of Rural Studies, 61: 244-254.

Paniagua, A. (2008). «La individualización del mundo rural. Dimensiones analíticas para ¿un concepto generalizable?». Economía, Sociedad y Territorio, 8(27): 639-659.

Phillips, L. (2006). «Food and globalization.»Annual Review of Anthropology, $35: 37-57$.

Pointereau, P.; Coulon, F.; Girard, P.; Lambotte, M.; Stuczynski, T.; SÁnchez, V.; Del Río, A. (2008). Analysis of farmland abandonment and the extent and location of agricultural areas that are actually abandoned or are in risk to be abandoned. Luxemburg: JRC Scientific and Policy Reports, European Union.

Polanyi, K. (1989). La gran transformación. Buenos Aires: Ediciones de la Piqueta.

Requena i Mora, M.; Alonso L. E.; Rodríguez Victoriano, J. M. (2018). «El campesinado ni se crea ni se destruye, solo se transforma. Discursos agrarios en el Delta de l'Ebre y l'Albufera de València». Política y Sociedad, 55(1): 161-188.

Rubio, P. (2010). «Modelización de los cambios y evolución reciente del sistema rural español». AGER, 54: 203-235.

SERVolin, C. (1977). «La absorción de la agricultura en el modo de producción capitalista». Zona Abierta, 12.

Sevilla-Guzmán, E. (2012). «Agroecología y agricultura ecológica: hacia una «re» construcción de la soberanía alimentaria». Agroecología, 1.

Soler, C.; Fernández, F. (2015). Estructura de la propiedad de tierras en España. Concentración y acaparamiento. Fundación Mundubat / Revista Soberanía Alimentaria, Biodiversidad y Culturas. 
Soronellas, M. (2012). «De la agricultura a la ruralidad. Estructura agraria, migraciones y globalización en Cataluña». História: Questões \& Debates, 56: 13-36.

SORonellas, M.; Bodoque, Y. (2016). «Iniciativas de reagrarización y producción alimentaria en Cataluña. Conciencia ecológica, identidad local y resistencia», a: III Seminário «Alimentos e Manifestações Culturais Tradicionais» i II Simpósio Internacional «Alimentação e Cultura: Tradição e Inovação na Produção e Consumo de Alimentos». Vila-Real (Portugal).

Soronellas, M.; CASAL, G. (2017). Pràctiques i estratègies de la pagesia a Catalunya. Trajectòries i plantejaments de futur. Barcelona: Associació Entrepobles.

Terres, J. M.; Nisini, L.; Anguiano, E. (2013). Assessing the risk of farmland abandonment in the EU. Luxemburg: JRC Scientific and Policy Reports, European Union.

Ustaoglu, E.; Collier, M. J. (2018). «Farmland abandonment in Europe: an overview of drivers, consequences, and assessment of the sustainability implications». Environmental Reviews, 26(4):396-416.

VAN DER PlOEG, J. (2018). «From de-to repeasantization: the modernization of agriculture revisited». Journal of Rural Studies, 236-243.

VAN Dijk, T.; KopeVA, D. (2006). «Land banking and Central Europe: future relevance, current initiatives, Western European past experience». Land Use Policy, 23: 286-301.

Vía CAmpesina (2018). jSoberanía Alimentaria ya! Una guía por la Soberanía Alimentaria. Disponible en línia. <https://viacampesina.org/en/wp-content/uploads/sites/2/2018/02/Food-Sovereignty-a-guide-ES-versionlow-res.pdf>. [Últim accés: 04/01/2020]. 